\title{
Differential Inhibition of Sphaeropsis sapinea Morphotypes by a Phenolic Compound and Several Monoterpenes of Red Pine
}

\author{
J. T. Blodgett and G. R. Stanosz
}

Department of Plant Pathology, University of Wisconsin-Madison, 1630 Linden Drive, Madison 53706-1598.

Accepted for publication 14 February 1997.

\begin{abstract}
Blodgett, J. T., and Stanosz, G. R. 1997. Differential inhibition of Sphaeropsis sapinea morphotypes by a phenolic compound and several monoterpenes of red pine. Phytopathology 87:606-609.

The in vitro effects of a red pine phenolic compound (pinosylvin), a phenolic compound common to other species (tannic acid), and the major red pine monoterpenes ( $\alpha$-pinene, $\beta$-pinene, and $\delta$-3-carene) on spore germination and mycelial growth of Sphaeropsis sapinea were examined. Two A and two B morphotype isolates were used. At $88 \mu \mathrm{g} / \mathrm{mm}^{2}$, pinosylvin inhibited spore germination of all four isolates (98 to 100\%). At $8.8 \mu \mathrm{g} / \mathrm{mm}^{2}$, spore germination of B isolates was inhibited more than that of A isolates (73 versus 30\%). Pinosylvin also inhibited mycelial growth

little affect on mycelial growth of either morphotype. Spore germination of $\mathrm{B}$ isolates was inhibited more than that of $\mathrm{A}$ isolates by $\beta$-pinene at saturation (79 versus $37 \%$ ). Spore germination of B isolates was inhibited and germination of $\mathrm{A}$ isolates was stimulated by $\delta$-3-carene below saturation (49 versus $-7 \%$ ). Mycelial growth of B isolates was inhibited more than that of A isolates by all monoterpenes at saturation. Differences observed between morphotypes below saturation were significant only for $\beta$-pinene. These results demonstrate the biological activity of a phenolic compound and monoterpenes that occur in red pine. The differential responses might provide means of distinguishing morphotypes and offer a potential explanation for ecological specialization.
\end{abstract} of B isolates more than that of A isolates ( 84 versus $13 \%$ at $88 \mu \mathrm{g} / \mathrm{mm}^{2}$ ). Tannic acid stimulated or had little affect on spore germination and had
Additional keywords: Diplodia pinea, Pinus resinosa.
Sphaeropsis sapinea (Fr.:Fr.) Dyko \& Sutton in Sutton (synonym Diplodia pinea (Desmaz.) J. Kickx fil.) causes shoot blight and canker diseases of pines and other conifers throughout the world. Two $S$. sapinea morphotypes (A and B) occur in the north central United States (18). Morphotypes are groups of individuals of a species with unknown or no taxonomic significance that can be morphologically differentiated (9). On red pine (Pinus resinosa Aiton), isolates of the A morphotype are more aggressive than isolates of the B morphotype (3).

Phenolic compounds and monoterpenes are hypothesized to be the main categories of chemicals involved in the resistance of pines to several fungal pathogens and insects $(14,16,19,22)$. These chemicals can occur in high concentrations in conifer species (up to several hundred milligrams per gram dry weight). They also can increase in abundance when trees are damaged mechanically or colonized by a pathogen. Monoterpenes are associated with the resistance of $P$. radiata to $S$. sapinea (4), and the resistance of $P$. elliottii to Cronartium quercuum $\mathrm{f}$. $\mathrm{sp}$. fusiforme has been correlated with the concentration of $\beta$-phellandrene in bark (21). However, Franich et al. (7) found little relationship between the monoterpene composition of $P$. radiata and resistance of mature trees to Dothistroma septospora.

The fungistatic properties of phenolics and monoterpenes have been documented in vitro. Phenolics and monoterpenes are inhibitory at concentrations observed in pines and other conifer species $(1,10,15,19)$. Previous studies have shown that monoterpenes inhibit a number of pine pathogens, including Heterobasidion annosum $(5,8,13)$, Leptographium spp. (15), Ophiostoma spp. (19), D. septospora (7), and Ceratocystis spp. (5). Tolerances to monoterpenes differ among species of decay and stain fungi $(6,11)$.

Corresponding author: J. T. Blodgett; E-mail address: JTB@plantpath.wisc.edu

Publication no. P-1997-0403-02R

(C) 1997 The American Phytopathological Society
Monoterpenes also inhibit a $S$. sapinea isolate of unknown morphotype (4).

Both phenolics and monoterpenes were studied in vitro. Phenolics included pinosylvin, the most common phenolic of red pine (12) and tannic acid, a common phenolic in other species. Monoterpenes included the three most common in red pine: $\alpha$-pinene, $\beta$ pinene, and $\delta$-3-carene. These comprise 59 to 74,13 to 33 , and 1 to $5 \%$, respectively, of the total monoterpenes in this species (2). The objectives were to examine (i) the effects of these phenolics and monoterpenes on spore germination and mycelial growth of $S$. sapinea and (ii) potential differences in the responses of the two morphotypes to these chemicals. The null hypotheses tested in this study were that (i) pinosylvin and monoterpenes have no affect on germination and growth of $S$. sapinea and (ii) morphotypes do not differ in their tolerance to these chemicals.

\section{MATERIALS AND METHODS}

Effects on spore germination. Conidia were produced for two monoconidial isolates of each morphotype (Table 1). Debarked and autoclaved red pine twig sections were placed on $1.5 \%$ water agar (WA; Difco Laboratories, Detroit) plates that were inoculated with colonized $1.5 \%$ WA plugs. Plates were incubated for 5 weeks at ambient laboratory temperature $\left(\sim 24^{\circ} \mathrm{C}\right)$ and light. Twigs on which pycnidia developed were scraped with a scalpel and washed with sterile distilled water to release conidia. The resulting suspensions were filtered through two layers of sterile cheesecloth. Conidial concentrations were estimated with a hemacytometer and adjusted to $\sim 1.25 \times 10^{3}$ conidia per $\mathrm{ml}$ with sterile distilled water. Conidial suspensions were kept on ice to prevent spore germination between collection, quantification, and plating.

Pinosylvin was obtained from D. Zinkel, USDA Forest Products Laboratory, Madison, WI. Commercially available tannic acid was used. Phenolics were dissolved in $80 \%$ aqueous acetone ( $\mathrm{vol} / \mathrm{vol}$ ) at concentrations of 0.2 and $0.02 \mathrm{mg} / \mathrm{ml}$. The solutions were applied and allowed to dry on the surface of $2 \%$ WA in multiwell 
tissue-culture plates (24-well; Becton Dickinson \& Company, Lincoln Park, NJ) at 88 and $8.8 \mu \mathrm{g} / \mathrm{mm}^{2}$. Eighty percent acetone was applied for controls. The acetone was allowed to evaporate in a laminar-flow hood. Conidial suspensions $(80 \mu \mathrm{l}$ per well) of each isolate were added.

Commercially obtained monoterpenes included (+/-)- $\alpha$-pinene (98\%), 1-(S)-(-)- $\beta$-pinene (99\%), and $\delta$-3-carene (95\%). Saturated atmospheres and vapor concentrations below saturation (70 and $10 \%$ of saturation) were compared. Different vapor concentrations were used, because the nonpolar, volatile monoterpenes cannot be dissolved in polar solvents. The conidial suspensions were added at $80 \mu \mathrm{l}$ per well to the multiwell tissue-culture plates containing $2 \%$ WA. Monoterpenes were placed on filter paper attached with paraffin wax to the lid above each well, and plates were quickly sealed. A single monoterpene at a single concentration was used for each plate. No monoterpenes were placed in control plates.

Vapor concentrations were estimated by gas-liquid chromatography (GLC) by applying various amounts of the monoterpenes to filter paper attached to the lid of the tissue-culture plates containing 2\% WA. GLC was performed using a modification of the procedures of Raffa and Steffeck (20) with a Schimadzu GC-9A gas chromatograph with flame ionization detector (Schimadzu Scientific Instruments, Columbia, MD) and the Alltech \#4839 capillary column ( $25 \mathrm{~m} \times 0.25 \mathrm{~mm}$; Alltech Associates, Deerfield, IL). Oven temperature was set at $60^{\circ} \mathrm{C}$, injector and detector temperature was $220^{\circ} \mathrm{C}$, and the carrier gas was helium at $30 \mathrm{~cm} / \mathrm{s}$, with a methane retention time of $84 \mathrm{~s}$. Vapor concentrations below saturation were estimated by peak integration with the Shimadzu C-R3A digital integrator (Schimadzu Scientific) and relative responses to the saturated atmospheres.

Both the phenolic and monoterpene plates were wrapped individually with plastic wrap and sealed inside two plastic bags. Plates were incubated at $25^{\circ} \mathrm{C}$ in the dark for $10 \mathrm{~h}$, after which germination was stopped by adding $0.1 \mu \mathrm{g}$ of thimerosol per ml. Plates were stored at $4^{\circ} \mathrm{C}$ in the dark between germination counts. Percent germination was determined from a minimum count of 50 spores

TABLE 1. Origin of Sphaeropsis sapinea isolates

\begin{tabular}{lcll}
\hline Isolate $^{\mathrm{a}}$ & Isolate no. $^{\mathrm{b}}$ & \multicolumn{1}{c}{ Host } & \multicolumn{1}{c}{ Geographic origin } \\
\hline A1 & 411 & Pinus resinosa & Clearwater Co., MN \\
A2 & 128 & P. resinosa & Grant Co., WI \\
B1 & 124 & P. banksiana & Jackson Co., WI \\
B2 & 215 & P. resinosa & Douglas Co., WI \\
\hline
\end{tabular}

${ }^{a}$ Morphotype and isolate number.

${ }^{\mathrm{b}}$ Culture collection numbers of M. A. Palmer.

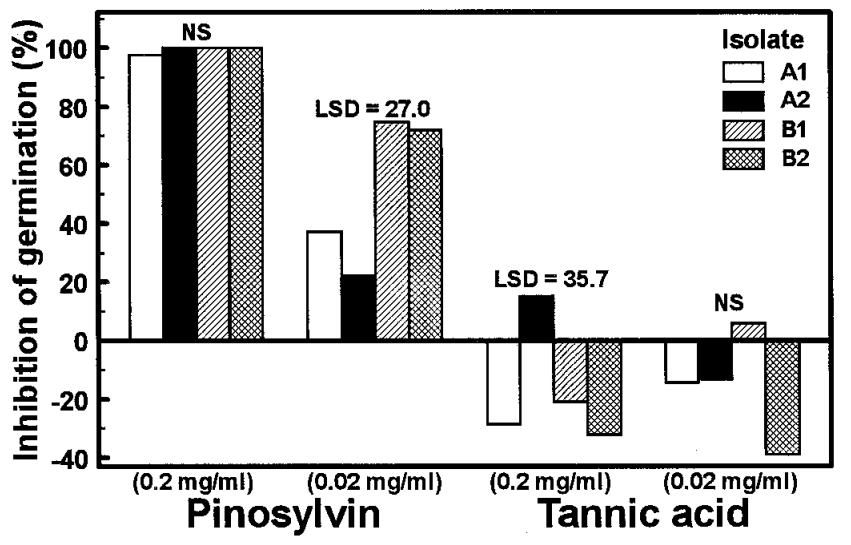

Fig. 1. Inhibition of conidial germination of two A and two B isolates of Sphaeropsis sapinea by pinosylvin and tannic acid after $10 \mathrm{~h}$. Pinosylvin and tannic acid were dried on the surface of water agar prior to application of conidia. Four replicates were used. The LSD values are Fisher's least significant differences for separating means at $P=0.05$. per well (range 50 to 89 ). Four replicates for each combination of isolate, chemical, and concentration were used.

Effects on mycelial growth. The phenolics (pinosylvin and tannic acid) were dissolved in $80 \%$ aqueous acetone (vol/vol) at concentrations of $0.2,0.02$, and $0.002 \mathrm{mg} / \mathrm{ml}$. The solutions were applied and allowed to dry on the surface of $2 \%$ WA in petri plates at $88,8.8$, and $0.88 \mu \mathrm{g} / \mathrm{mm}^{2}$. Eighty percent acetone was applied for controls. The acetone was allowed to evaporate in a laminarflow hood. Colonized $1.5 \%$ WA plugs, $4 \mathrm{~mm}$ in diameter, were cut from margins of actively growing cultures and placed fungus side down at the edge of the agar in the petri plates. Plates were wrapped with Parafilm. The isolates used were the same ones described above.

Monoterpenes were placed on filter paper at the bottom of $2 \%$ WA slants that had rubber-lined screw-top closures (Kimble Glass, Vineland, NJ). Monoterpene vapor concentrations were estimated by GLC with commercially obtained monoterpenes. Saturated atmospheres and vapor concentrations below saturation $(80,66$, and $32 \%$ of saturation) were compared. Colonized $1.5 \%$ WA plugs, $4 \mathrm{~mm}$ in diameter, were cut from margins of actively growing cultures and placed fungus side down on agar at the top of the slants. The slants were sealed, creating saturated atmospheres. No monoterpenes were placed on filter paper in control slants.

Plates and slants were incubated at $25^{\circ} \mathrm{C}$ in the dark. Radial growth of the cultures was recorded at 2 weeks. Five replicates for each combination of isolate, chemical, and concentration were used.

Statistical analyses. For comparisons of germination and mycelial growth, inhibition percentages were calculated $(\%$ inhibition $=$ (control - treatment)/control $\times 100)$. Inhibition percentages were analyzed by one-way analyses of variance (ANOVAs). If significant differences were found $(P \leq 0.05)$, means were separated by Fisher's least significant difference (LSD) at $P=0.05$. ANOVAs (using the general linear model procedure) were performed with the Minitab for Windows program, release 10.2 (Minitab, Inc., State College, PA).

\section{RESULTS}

Effects on spore germination. Pinosylvin inhibited germination of both morphotypes, but tannic acid had little effect on germination (Fig. 1). The average percent germination for controls was $56 \pm 2.3 \%$ standard error (SE) for A isolates and $45 \pm 2.6 \%$ $\mathrm{SE}$ for B isolates. At the highest concentration, pinosylvin inhibited germination of all isolates with no differences between morphotypes. Germination was less inhibited at one-tenth concentra-

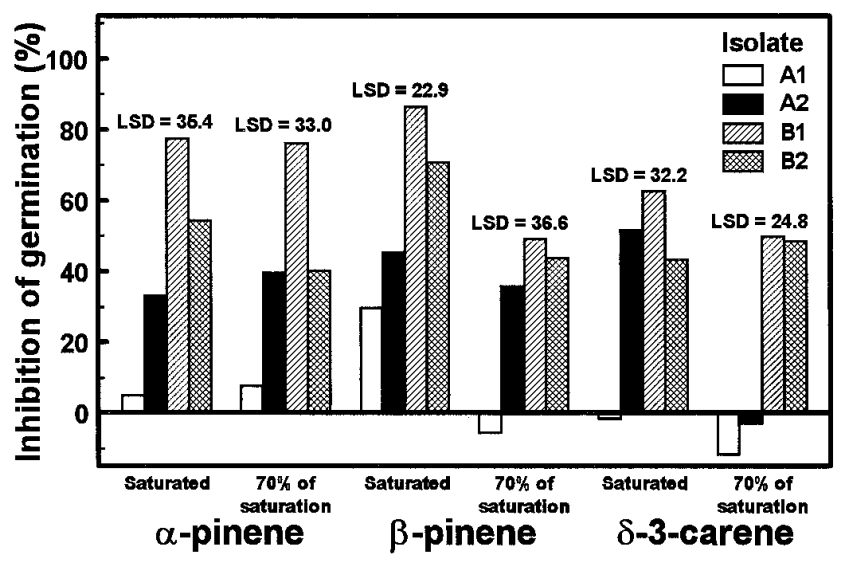

Fig. 2. Inhibition of conidial germination of two A and two B isolates of Sphaeropsis sapinea by $\alpha$-pinene, $\beta$-pinene, and $\delta$ - 3 -carene after $10 \mathrm{~h}$. Conidia were placed on the surface of water agar and exposed to different atmospheres of the monoterpenes. Four replicates were used. The LSD values are Fisher's least significant differences for separating means at $P=$ 0.05 . 
tion, but $\mathrm{B}$ isolates were inhibited more than $\mathrm{A}$ isolates $(P=0.002)$. Tannic acid either stimulated germination or had little influence on either morphotype at either concentration.

Saturated atmospheres of the monoterpenes inhibited germination of both morphotypes (Fig. 2). The average percent germination for controls was $62 \pm 1.9 \%$ SE for A isolates and $49 \pm 2.4 \%$ $\mathrm{SE}$ for B isolates. Responses of morphotypes differed only at saturated atmosphere for $\beta$-pinene $(P=0.001)$ and at $70 \%$ saturation for $\delta$-3-carene $(P<0.001)$. In both cases, B isolates were inhibited more than A isolates. There was little inhibition and morphotypes could not be differentiated at $10 \%$ of saturation (data not shown). Compared to other monoterpenes, $\beta$-pinene was more inhibitory at saturation.

Effects on mycelial growth. Pinosylvin inhibited radial growth of both morphotypes, and tannic acid had little effect on growth of either morphotype (Fig. 3). The average mycelial growth for controls was $46 \pm 0.9 \mathrm{~mm} \mathrm{SE}$ for A isolates and $42 \pm 0.5 \mathrm{~mm} \mathrm{SE}$ for $\mathrm{B}$ isolates. Pinosylvin inhibited mycelial growth of $\mathrm{B}$ isolates more than A isolates at both 0.2 and $0.02 \mathrm{mg} / \mathrm{ml}(P<0.001)$. There was little inhibition and morphotypes could not be differentiated at $0.002 \mathrm{mg} / \mathrm{ml}$ (data not shown). Tannic acid had a similar influence on $\mathrm{A}$ isolates and was less inhibitory to $\mathrm{B}$ isolates compared to pinosylvin at all concentrations.

The monoterpenes inhibited radial growth of both morphotypes (Fig. 4). However, all three monoterpenes inhibited radial growth of B isolates more than A isolates at saturated atmospheres $(P<$ $0.001)$. The average mycelial growth for controls was $35 \pm 1.2$ $\mathrm{mm} \mathrm{SE}$ for A isolates and $44 \pm 1.1 \mathrm{~mm} \mathrm{SE}$ for B isolates. Differences between morphotypes at both 80 and $66 \%$ of saturation were significant only for $\beta$-pinene $(P<0.001)$. There was little inhibition at 66 and $33 \%$ of saturation for any of the monoterpenes (data not shown).

\section{DISCUSSION}

Examination of the effects of host phenolic compounds and monoterpene may provide additional means of differentiating morphotypes of $S$. sapinea. The two $S$. sapinea morphotypes have different colony morphology, growth rates on potato dextrose agar, mean spore sizes, and isozymes (18). S. sapinea isolates also can be differentiated into morphotypes using random amplified polymorphic DNA analyses (23). The differential inhibition of these two morphotypes by monoterpenes and pinosylvin provides further justification for distinguishing different types and might help explain differences in the response of red pine to A and B morphotypes.

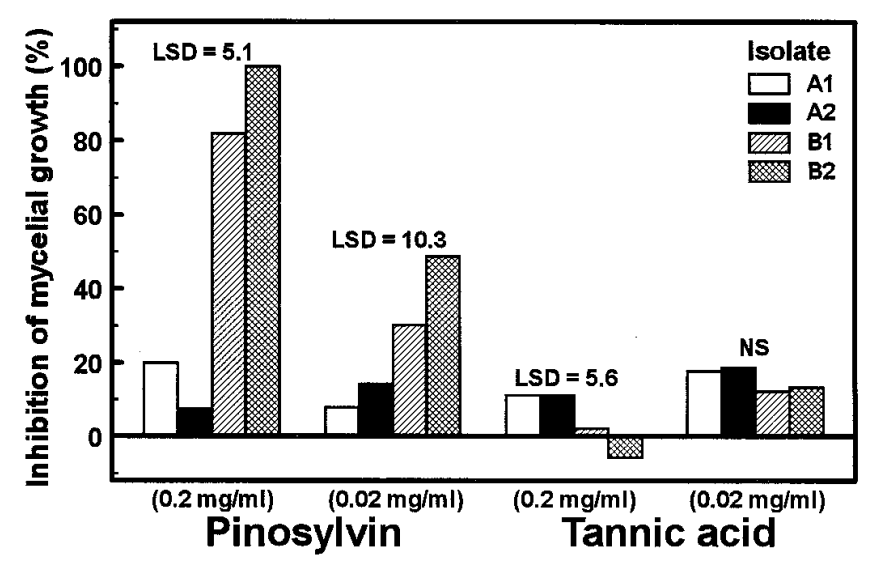

Fig. 3. Inhibition of mycelial growth of two A and two B isolates of Sphaeropsis sapinea by pinosylvin and tannic acid after 2 weeks of incubation. Pinosylvin and tannic acid were dried on the surface of water agar prior to application of a colonized agar plug. Five replicates were used. The LSD values are Fisher's least significant differences for separating means at $P=0.05$.
Previously reported differences in aggressiveness between morphotypes on red pine (3) may result from variable responses to host chemicals. Our bioassays show that pinosylvin and several monoterpenes that occur in red pine inhibit A and B morphotypes of $S$. sapinea in vitro. Although these chemicals are inhibitory to $S$. sapinea, the isolates tested differ in their tolerances to these chemicals.

The inhibitory effects of $\alpha$ - and $\beta$-pinene on A isolates were similar to those reported by Chou and Zabkiewicz (4) for an isolate of unknown morphotype. Monoterpenes were more inhibitory to germ tube growth than to germination for a single $S$. sapinea isolate of unknown morphotype (4). In the current study, mycelial growth was inhibited more than spore germination when $S$. sapinea was exposed to the monoterpenes. In the previous study, germ tube growth over $6 \mathrm{~h}$ was reduced by $\alpha$ - and $\beta$-pinene and $\delta$-3-carene by $\sim 70$ to $80 \%$ at saturated atmospheres (4), which is similar to percentages observed for mycelial growth of $\mathrm{A}$ isolates in this study. Chou and Zabkiewicz (4) found $\delta$-3-carene to be the most inhibitory of the monoterpenes on spore germination. In this study, there were no clear differences between monoterpenes.

Phenolic extracts of red pine are inhibitory to other fungal pathogens. Consistent with our results for B isolates, Klepzig et al. (15) found that phenolic extracts of red pine (primarily pinosylvin and its monomethyl ether) inhibited mycelial growth of $L$. terebrantis and L. procerum. In our study, mycelial growth of B isolates was substantially inhibited by pinosylvin, but there was little effect on A isolates. Although in our study germination of both morphotypes was substantially reduced by pinosylvin, phenolic extracts of red pine did not affect germination of the Leptographium spp. (15). Thus, the effects of red pine phenolics may vary with different pathogens or assay conditions.

Differences between morphotypes in response to these chemicals are consistent with differences in aggressiveness on red pine and might offer evidence for ecological specialization of the morphotypes. Conifers react to colonization by pathogens by forming resinous lesions in phloem and sapwood around infection sites $(14,17,19)$. The B types are restricted in red pine to the immediate vicinity of the inoculation site, but A isolates can spread, girdle, and kill red pine shoots (3). Pinosylvin and monoterpenes may inhibit the growth of $\mathrm{B}$ isolates, preventing colonization. Collection of isolates of the B morphotype only from wounded trees suggests they are opportunistic colonizers of damaged or weakened host tissues $(18,24)$. The success of the B morphotype in these tissues may reflect inhibition of normal pine defensive responses, including reductions in normally inhibitory concentrations of red pine monoterpenes and phenolics.

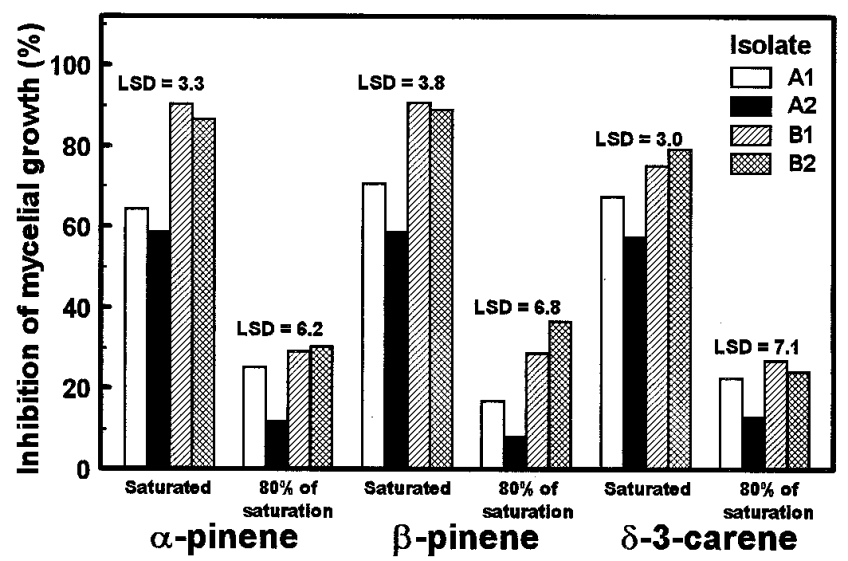

Fig. 4. Inhibition of mycelial growth of two A and two B isolates of Sphaeropsis sapinea by $\alpha$-pinene, $\beta$-pinene, and $\delta$ - 3 -carene after 2 weeks of incubation. Cultures were grown on water agar and exposed to different atmospheres of the monoterpenes. Five replicates were used. The LSD values are Fisher's least significant differences for separating means at $P=0.05$. 


\section{ACKNOWLEDGMENTS}

The partial financial support of the USDA (Hatch) is gratefully acknowledged. We thank K. Raffa and J. Buck for presubmission review, R. A. Dean and two anonymous reviewers for helpful suggestions, M. Clayton for statistical advice, and M. Palmer for cultures. We also thank D. Smith for technical assistance.

\section{LITERATURE CITED}

1. Alcubilla, M., Diaz-Palacio, M. P., Kreutzer, K., Laatsch, W., Rehfuess, K. E., and Wenzel, G. 1971. Beziehungen zwischen dem Ernährungszustand der Fichte (Picea abies Karst.) ihrem Kernfäulebefall und der Pilzehemmwirkung ihres Basts. Eur. J. For. Pathol. 1:100-114.

2. Blodgett, J. T. 1996. The effects of host water stress on disease development by different Sphaeropsis sapinea morphotypes. Ph.D. dissertation. University of Wisconsin-Madison, Madison.

3. Blodgett, J. T., and Stanosz, G. R. 1997. Sphaeropsis sapinea morphotypes differ in aggressiveness, but both infect nonwounded red or jack pines. Plant Dis. 81:143-147.

4. Chou, C. K. S., and Zabkiewicz, J. A. 1976. Toxicity of monoterpenes from Pinus radiata cortical oleoresin to Diplodia pinea spores. Eur. J. For. Pathol. 6:354-359.

5. Cobb, F. W., Jr., Krstic, M., Zavarin, E., and Barber, H. W., Jr. 1968. Inhibitory effects of volatile oleoresin components on Fomes annosus and four Ceratocystis species. Phytopathology 58:1327-1335.

6. De Groot, R. C. 1972. Growth of wood-inhabiting fungi in saturated atmospheres of monoterpenoids. Mycologia 64:863-870.

7. Franich, R. A., Gaskin, R. E., Wells, L. G., and Zabkiewicz, J. A. 1982. Effect of Pinus radiata needle monoterpenes on spore germination and mycelial growth of Dothistroma pini in vitro in relation to mature tree resistance. Physiol. Plant Pathol. 21:55-63.

8. Gibbs, J. N. 1968. Resin and the resistance of conifers to Fomes annosus. Ann. Bot. 32:649-665.

9. Hawksworth, D. L., Kirk, P. M., Sutton, B. C., and Pegler, D. N. 1995. Ainsworth and Bisby's Dictionary of the Fungi. 8th ed. International Mycological Institute, Egham, England.

10. Hergert, H. L. 1960. Chemical composition of tannins and polyphenols from conifer wood and bark. For. Prod. J. 10:610-617.
11. Hintikka, V. 1970. Selective effect of terpenes on wood-decomposing Hymenomycetes. Karstenia 11:28-32.

12. Jorgensen, E. 1961. The formation of pinosylvin and its monomethyl ether in the sapwood of Pinus resinosa Ait. Can. J. Bot. 39:1765-1772.

13. Kennedy, R. W. 1956. Fungicidal toxicity of certain extraneous compounds of Douglas-fir heartwood. For. Prod. J. 6:80-84.

14. Klepzig, K. D., Kruger, E. L., Smalley, E. B., and Raffa, K. F. 1995. Effects of biotic and abiotic stress on induced accumulation of terpenes and phenolics in red pines inoculated with bark beetle-vectored fungus. J. Chem. Ecol. 21:601-626.

15. Klepzig, K. D., Smalley, E. B., and Raffa, K. F. 1996. Combined chemical defenses against an insect-fungal complex. J. Chem. Ecol. 22:1367-1388.

16. Lieutier, F., and Berryman, A. A. 1988. Preliminary histological investigations of the defense reactions of three pines to Ceratocystis clavigera and two chemical elicitors. Can. J. For. Res. 18:1243-1247.

17. Nebeker, T. E., Hodges, J. D., and Blanche, C. A. 1993. Host response to bark beetle and pathogen colonization. Pages 157-173 in: Beetle-Pathogen Interactions in Conifer Forests. T. D. Schowalter and G. M. Filip, eds. Academic Press, San Diego, CA.

18. Palmer, M. A., Stewart, E. L., and Wingfield, M. J. 1987. Variation among isolates of Sphaeropsis sapinea in the north central United States. Phytopathology 77:944-948.

19. Raffa, K. F. 1991. Induced defensive reactions in conifer-bark beetle systems. Pages 245-276 in: Phytochemical Induction by Herbivores. D. W. Tallamy, ed. John Wiley \& Sons, New York.

20. Raffa, K. F., and Steffeck, R. J. 1988. Computation of response factors for quantitative analysis of monoterpenes by gas-liquid chromatography. J. Chem. Ecol. 14:1385-1390.

21. Rockwood, D. L. 1974. Cortical monoterpene and fusiform rust resistance relationships in slash pine. Phytopathology 64:976-979.

22. Shrimpton, D. M. 1973. Extractives associated with wound response of lodgepole pine attack by the mountain pine beetle and associated microorganisms. Can. J. Bot. 51:527-534.

23. Smith, D. R., and Stanosz, G. R. 1995. Confirmation of two distinct populations of Sphaeropsis sapinea in the north central United States using RAPDs. Phytopathology 85:699-704.

24. Wingfield, M. J., and Palmer, M. A. 1983. Diplodia pinea associated with insect damage on pines in Minnesota and Wisconsin. Page 249 in: Proc. 4th Int. Congr. Plant Pathol. University of Melbourne, Melbourne, Australia. 